\title{
The Development of a
}

\section{Sustainability Model for the}

Integration and Use of an

African Language as a Language of

Learning and Teaching in Higher Education

\section{Rosemary Wildsmith}

\begin{abstract}
This paper discusses the organic development of a Sustainability Model for the implementation of an African language, viz. Zulu, as a language of learning and teaching (LoLT) at tertiary level in a South African University. The model created the conceptual framework for research into and implementation of Zulu as a medium of instruction in selected subject areas at University level. The aim of this project is to promote multilingualism in higher education. It has been funded by the South Africa-Norway Tertiary Education Development (SANTED) programme. This article traces the initial development of this model, which drew on the findings of various research studies over a period of ten years, culminating in its application to the development of specialist discourse and terminology in Zulu in specific subject areas in the Social Sciences, Health Sciences and Humanities curricula. The project involved the collaboration of various subject specialists in Psychology, Nursing, Dentistry and Education (Foundation Phase level). The implementation has been two-fold: the offering of basic communication skills courses in Zulu for non-Zulu-speaking staff and students involved in the above professional disciplines, and terminology development in the respective disciplines in order to enable the use of Zulu in selected materials and tutorial groups. This SANTED-funded initiative (2006) has been a systematically-planned and deliberate intervention on the
\end{abstract}


part of lecturers and researchers to introduce an African language as a potential LoLT, whilst at the same time contributing to the intellectualisation of the language in question.

Keywords: language acquisition, isiZulu, multilingualism, second language learning, second language teaching, language intellectualisation, language development and promotion, medium of instruction

\section{Introduction}

In response to SANTED's call for projects which addressed multilingualism in order to promote access and retention in higher education, the University of KwaZulu-Natal (UKZN), together with the Durban University of Technology (DUT), submitted a proposal addressing three main focus areas. These were the acquisition of additional languages, specifically, an indigenous language, for students registered for professional programmes which involves working closely with the general public such as the Health Sciences, Social Sciences and Education; short courses in basic communication skills in Zulu to promote multilingualism amongst university staff and students, and the piloting of an integrated approach using Zulu as a language of learning and teaching in class sessions and tutorials in selected disciplines. These three focus areas were perceived as interdependent and mutually supportive and led to further objectives for the project: the translation of materials in the professional disciplines into Zulu; terminology development workshops, and workshops for capacity-building and the continued professional development of Zulu language teaching specialists. The overall objective for the project, therefore, has been sustained language acquisition and development for both staff and students in selected professional areas, involving collaboration among staff in the specialist disciplines, Zulu language specialists and Applied Linguistics specialists across the institutions. A Sustainability Model for the acquisition, development and integration of Zulu as a LoLT in selected professional disciplines provided the overall conceptual framework for the project. 


\section{The Sustainability Model}

The Sustainability Model was founded on key research insights into the processes of language acquisition, one of these being that language learning is developmental (Ellis 1985; 1994) and incremental, and thus needs to be sustained over time through exposure to and use of the language in real-life situations for genuine communicative purposes (Wildsmith-Cromarty 2003a). In a higher education institution, using the language as a LoLT in certain subject areas ensures active and repeated use of the language in an academic setting, which supports the development of cognitive academic language proficiency (CALP) (Cummins 2000) for both mother tongue/primary language and additional language speakers. An observation from Doughty and Long (2003:4) make this point clear:

... language learning, like any other learning, is ultimately a matter of change in an individual's internal mental state. As such, research on SLA is increasingly viewed as a branch of cognitive science.

This method of facilitating language acquisition whilst simultaneously teaching subject content is know as Content-based Language Instruction (CBI). This approach has been implemented in both Canada and the USA very effectively (Brinton, Snow \& Wesche 1989) and entails a language teaching method whereby content subjects are taught through a second language with dual aims: the learning of subject content, and the simultaneous acquisition of the additional language. Learning subject content through the medium of another language preserves linguistic and cultural diversity and opens the way to increased intercultural and international communication. This is essentially what Luckett (1995) refers to as an additive bilingual education model. In a similar way, the SANTED project encourages the sustained use and development of more than one of the official languages in a tertiary education setting. At the same time, it also attempts to foster increased linguistic and communication skills in professional trainees working with indigenous communities in South Africa.

In the SANTED project, both Zulu and English are used thus enabling further acquisition of both languages. In the same way, work experience, where the language is used with clients in professional settings, also provides opportunities for practice and further supports the development 
of basic interpersonal communication skills (BICS) (Cummins 2000). This could also be regarded as a form of language socialization (Watson-Gegeo \& Nielsen 2003) whereby the context of language use drives acquisition. This is a Vygotskian (1978) approach to the negotiation of comprehensible input (Krashen 1985) in social interaction in which learners are pushed to communicate beyond their actual competence levels. The use of a contentbased approach to language learning also encourages further development of the language itself as terminology needs to be created for the relevant concepts. The model was initially conceptualized in terms of four phases, although the project encompassed the first three only. The fourth phase was considered as a goal to be attained over the longer term.

Figure 1: Sustainability Model

\section{Phase 1: Language Acquisition Phase}

Development of BICS Short, basic course in Zulu

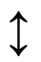

in language skills

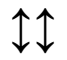

Development of model of best practice

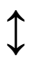

Translation of course materials skecialist discourse

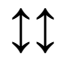

Phase 3: Extension Phase
Work Experience Development of IT

for further induction expertise for into specialist discourse academic purposes

\section{Apprenticeship Phase}

Team-teaching with content specialist Interpreting
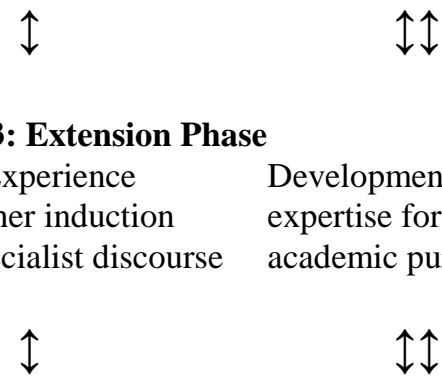

Phase 4: Bilingual Teaching

Selected modules offered in Zulu only or in both English and Zulu
Home Stays for consolidation of communication skills

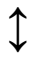

Full bilingual degree One major in Zulu One major in English 
Phase 1 is the language acquisition phase where the focus is on developing basic interpersonal communication skills (BICS) (Cummins 2000) in Zulu for non-Zulu staff and students. Related to this is a further focus on developing a 'best practice' pedagogic model for the teaching of Zulu as an additional language in a short course.

Phase 2 is the integration phase and entails the creation of partnerships involving Zulu specialists and content specialists in selected disciplines. This phase involves the integration of some use of Zulu in tutorial sessions where classes are mixed in terms of Zulu/non-Zulu speakers, and the sole use of Zulu as LoLT where classes are comprised solely of Zulu speakers. The integration of Zulu into a discipline-specific academic discourse facilitates access to the discourse of the discipline for Zulu native speakers, and also enables non-native speakers to gain a working knowledge of the language for professional purposes. This creates the need for the translation of selected materials into Zulu, and the development of appropriate terminology. It also requires team-teaching, either with a Zulu colleague in the discipline, or with a Zulu specialist as interpreter/facilitator.

Phase 3 is the extension phase where language development is sustained by means of contact with the community through work experience. Ideally, students working in their professional contexts either part-time or during vacation periods will draw on their knowledge of the language during their internships, clinical sessions and teaching practice when dealing with health professionals, hospital patients, caregivers, teachers and children. This would also facilitate further induction into the professional discourse. Further contact with the speech community is envisaged through 'home-stays' for the consolidation of the basic communication skills. A third aim in Phase 3 is the development of expertise in Information Technology for general academic purposes such as sourcing (or developing) language learning programmes in Zulu or encouraging the use of on-line messaging on various topics.

Phase 4 would be the ultimate target of the developmental process during the first three phases-bilingual learning and teaching, where selected modules in the professional programmes could be taught in one or other language, or both. An alternative development in this phase could take the form of a 
bilingual degree programme with two majors: one taught in Zulu and the other in English. Each stream would comprise various modules drawn from both the discipline of Zulu Studies, and a specialist discipline such as Applied Language Studies. An example of such a degree programme at the University of Limpopo has been documented elsewhere (Ramani et al, 2007). The researchers implemented a dual-medium undergraduate degree in both Northern Sotho and English in an attempt to implement an additive bilingual model of education at tertiary level. What is interesting about their approach is that they worked from the bottom-up and grounded terminology development in their daily experience of pedagogic practices. They achieved this through getting learners to engage with cognitively challenging tasks that led to the assimilation of new concepts. They maintain that terminology for discipline-specific purposes can be developed very effectively through pedagogic processes, and that acquisition planning can indeed precede corpus planning in this way. They conclude that:

Such a pedagogically-responsive and discourse-embedded use of terminology locates the site of resource building for African languages within the pedagogic use of these languages as media of instruction (207)

To some extent, this was the approach adopted by certain partner disciplines in the SANTED project, particularly psychology and nursing, where terms were created in workshop contexts with various stakeholders as the need arose.

\section{Background to the Development of the Model Initial Research Studies}

The research studies which underpinned the development of what eventually became the current model will now be described.

Three research studies fed into the organic development of the model from its inception in 1999 to its implementation in 2005. Two of these studies investigated various aspects of the acquisition of Zulu as an additional language at both secondary and tertiary levels. Findings from these two studies then fed into the third study, which involved research into 
...Use of an African Language as a Language of Learning and Teaching ...

the development and implementation of a course on the teaching of Zulu as an additional language to second and third year Zulu mother tongue students at university.

Research Study 1-The Acquisition of Zulu Morphology by School Learners

The first study was on the acquisition of Zulu morphology by grade 6 and 7 learners at selected secondary schools in KwaZulu-Natal (WildsmithCromarty 2003b). The investigation was motivated by the desire to learn more about the acquisition of Zulu as an additional language in order to teach it more effectively. The focus of the study was on the relative ease of acquisition of the identificative copulative and the noun class and agreement system in varying contexts and with reference to both spoken and written modalities. Varied tasks were used to examine learner performance as it has been shown (Romaine 2003:409) that grammatical accuracy can vary depending on task demands 'with more target-like performance typically more frequent on formal tests than in casual conversations'. The study was both longitudinal and cross-sectional in nature, with data being collected at intervals over a two-year period. Tasks were both form-focused and meaning-focused, consisting of informal letters to a Zulu-speaking pen-pal and a more structured interview.

The findings from this study revealed both omission and overgeneralization (Ellis 1994) of noun class prefixes and subject markers, and the further identification of two types of morphemes in the same system, which Suzman (1991:8), on the basis of her own research into first language acquisition of Zulu, referred to as Type 1 and Type 2 morphemes. Type 1 morphemes are learned in association with the noun, such as the adjective or object markers in the phrases abafana abajabulayo 'happy boys' and izicathulo engizithandayo 'favourite shoes'. Type 2 morphemes are rulelearned as pronouns and carry 'an anaphoric, multipurpose element for L1 children' (Suzman 1991:8). This type of morpheme is more difficult to learn for both L1 and L2 learners as it is not learned in association with the noun (Suzman 1991 1999). It is thus more susceptible to overgeneralization and, in the case of L2 learners, confusion. An example would be the overgeneralization of the subject marker / $i$ / in the context of a Class 5 noun 
which should normally take the SM /li/ as in iphi ibhola instead of liphi ibhola: 'Where is the ball?'. The important factor here for L2 learners in particular was the nature and degree of exposure to these morphemes in naturalistic contexts, which, in turn, held implications for second language pedagogy and course design.

The findings from this study were analyzed in terms of an interlanguage (Selinker 1992) theoretical framework with a focus on variability as a crucial explanatory construct. Interlanguage is considered as an interim system in its own right which sits somewhere between the learner's primary language (L1) and the target language (TL). It is permeable, dynamic and systematic and consists of formulas or chunks in the early stages, constructed from the use of strategies such as pattern imitation, memorization, partial pattern analysis, substitution and analogy. The latter stages of interlanguage are characterized by rules and hypotheses once learners have begun to internalize the linguistic system. Among the cognitive strategies used at this point are pattern analysis, inference, expansion, simplification and overgeneralization. Interlanguage variation, however, may also be defined by the learner's current level of processing, and the limitations that this has for the acquisition of various structures at a given point in time. Pienemann's (2003:686) processability theory offers an alternative perspective on the phenomenon of interlanguage, viewing language learning as incremental in that at any given stage of development 'the learner can produce and comprehend only those L2 linguistic forms which the current state of the language processor can manage'.

The insights gained from the findings of this study fed directly into the development of a course on teaching Zulu as an additional language for third year mother tongue Zulu students at tertiary level aspiring to become teachers of Zulu at secondary school level. This course also represented the beginning stages of the development of the Sustainability Model in question as the findings from the research into the acquisition of Zulu morphology formed part of the content of the course.

\section{Research Study 2-Learning Zulu as an Additional Language at Tertiary Level \\ Running parallel to the above study into the acquisition of morphology by}


secondary school learners was a second, longitudinal study into the acquisition of Zulu as an additional language by first year students at a South African university (Wildsmith-Cromarty 2003a). The initial research was conducted over a year and took the form of a diary study of one learner's experiences of learning Zulu at first-year level, supplemented by data from responses to questionnaires by her co-learners in the same class. The study was motivated by the desire to revise both syllabus and curriculum for the teaching of basic communication skills in Zulu at tertiary level. Lecturers were concerned that students would emerge from a major in Zulu and not be able to hold a basic conversation in the language. The researcher-learner, who was an applied linguist with a specialization in language acquisition, decided to enrol for the first-year course in order to gain insights into the curriculum, materials and pedagogy from the learners' perspective. It was felt that course design would be best informed from the 'bottom-up' and that tasks and activities might be more appropriate if they were designed according to what learners found challenging, and also according to the way learners learned the specific language system under study. This latter aspect tallied with the findings from the school study on the acquisition of morphology.

Especially significant to the course design for the Zulu students aspiring to teach Zulu as an additional language was the way grammar was presented and taught in the original Zulu first year course (Wildsmith Gordon \& Godlonton 2007). The approach was traditional, having a structural focus and using the grammar-translation method to teach both syntax and vocabulary. Vocabulary was presented in the form of decontextualized items in lists, categorized according to the various noun classes in Zulu. This forced a rote-memorization strategy on the part of the students and, in addition, enhanced the learners' confusion regarding the morphology of the language, which, in turn, encouraged either omission or overgeneralization of noun class prefixes and subject markers. This phenomenon had been noted earlier in the findings of the school study on the acquisition of Zulu morphology (Wildsmith-Cromarty 2003b).

In response to the distinction made in the earlier school study between Type 1 and Type 2 morphemes, lecturers and researchers involved in the university study decided to design course materials for teaching Zulu morphology according to this distinction. They thus designed materials that 
would highlight the pervasive noun class and agreement system by presenting vocabulary items (a) within a context containing lexical items belonging to a particular noun class, eg. NC 5, which carries the NC prefix /i/ for naming objects in a classroom, and (b) presenting expanded noun phrases (as opposed to isolated nouns) where the agreement is clearly perceptible, such as adjectives with nouns (eg. abantwana abancane 'small children'; isinkwa esimnandi 'tasty bread'), or structures where the object marker clearly agrees with the NC prefix (eg. umculo engiwuthandayo 'song which I like' 'my favourite song'; isifundo engisithandayo ' subject which I like' 'my favourite subject'). Findings from this study thus held major implications for the teaching of basic communication skills courses in Zulu which were subsequently fed into the development of the course on teaching Zulu as an additional language. This latter course, which is described in more detail below, served as the basis for the development of a Sustainability Model for language acquisition.

\section{Research Study 3-A Bilingual Model for Course Design}

The third study focused on research into and development of a course on the teaching of Zulu as an additional language using a dynamic, bilingual approach to the production of knowledge in order to facilitate learning. One of the main aims underlying this course was to explore the effects on student learning and performance of using two languages of instruction. It was thus fundamental to the conceptualization and design of the Sustainability Model as it allowed for the use of both English and Zulu as languages of learning and teaching (LoLTs) in a content subject. The research approach adopted in relation to this course was essentially exploratory-interpretive in the early stages of its implementation as the researcher wished to examine the interaction between the two languages as it occurred naturally and spontaneously among the various participants in class. To this purpose, each session was audio-taped in order to monitor the nature and function of the mother tongue/primary language in the classroom in order to inform future pedagogy. Data was analyzed within a broad discourse analysis framework, the focus being on the use and function of Zulu where and whenever it occurred in the general classroom interaction. 
The course was a semester course consisting of both input and practical sessions. A major goal was to induce in the student trainees an understanding of the language acquisition process from the learners' perspective. To this end, data from the two research studies described above were used as examples of learner language which the student trainees were required to analyze. The course required critical assessment of various theoretical positions on the learning and teaching of additional languages; an understanding of the differences between naturalistic and instructed language learning and the implications of these for teaching; matching of learner needs with appropriate methodologies, activities and content and application of their understanding of the processes involved to the development of proficiency in the four skill areas of listening, speaking, reading and writing. Assessment was in the form of regular practical exercises, a major assignment, tests and a final examination. The purpose of the practical exercises was to help students gradually build up a frame of reference which was comprised of crucial concepts in the discourse of the discipline. The major assignment was intended as a consolidation of this knowledge in its application to real data. Students were free to use either English or Zulu in class sessions and were allowed to respond in either language in their examinations. In the first two years of teaching the course, however, students were required to use English in their practical exercises and assignments in order to assess whether they had indeed understood important concepts in the discipline. This was because the use of Zulu in class was not systematic or pre-planned in any way with the result that many of the concepts specific to the discipline were not necessarily translated into their equivalents in Zulu. For some assignments, however, they were asked to respond in both English and Zulu in order to assess how well they managed to express key concepts in both languages.

Pedagogy for this course involved team teaching by an applied linguist who was the subject specialist in terms of language learning and teaching theory, and a Zulu specialist who was responsible for acting as translator and facilitator in class sessions. The main language of instruction for presenting substantive content was English, and the applied linguist was the person responsible for this. Each session would thus begin with an English presentation of the content. The Zulu teacher would then translate, paraphrase or elaborate on the content in Zulu in order to ensure 
understanding. This, in turn, would trigger responses from the students in Zulu, leading to lengthy interactions in this language before the applied linguist would attempt to summarize the discussions in English again before moving on to the next concept. In this way, English was used to present the conceptual content, and Zulu was used to facilitate understanding of these concepts. This led to a 'code-switching' approach where students and lecturers used both English and Zulu interchangeably - the kind of pedagogic interaction proposed in Phase 3 of the Sustainability Model. An example is provided below. Each interactional 'turn' is numbered.

\section{Example 1}

[The class are discussing the meaning of 'mother tongue' and trying to arrive at a definition]

[Key: ZL = Zulu lecturer; AL = Applied linguistics lecturer; S1 = Student 1; S2 = Student 2; S3= Student 3]

1. ZL: Do people know what's 'mother tongue'? Do people all know that?\}

2. S1: Ja....?\}

3. AL: What do you call it in isiZulu?

4. ZL: Ulimi...Ulimi lwakho...your language......

5. AL: .....Ulimi lwakho?(your language)

6. ZL: ....or Ulimi lwasekhaya (home language)

7. AL:... and if you speak three then which one are you talking about?

8. AL: ....wasekhaya....(home)

9. ZL....Iwasekhaya...ja...um....most people will say all three...or that's what I would do....you can't specify which is the exact one, if you speak three...\}

11. S1: Three...? Like....

12. ZL: ...uma ukhuluma izilimi ezinthathu..ukhuluma kodwa (if you speak three languages...you speak, but...) ..What do you say? Which is your mother tongue?

13. S1: NjengoMa nje (like my mother). Umama ukhuluma... (Mother speaks...)....

14. ZL: ...isiZulu, isiNgisi, isiBhunu....

15. S2: Kodwa kukhona ....hhayi!! (But there is.....No..!)\} 
...Use of an African Language as a Language of Learning and Teaching ...

16. S3: Ngeke ukukhulume ngokufana....(No way can you speak it/all in the same way) $\}$

17. S2: Hhayi ngeke! (No way!)\}

18. ZL: Kokubili, kokuthathu ..... (be it two or be it three...)...kuyafana...(it is the same)...

19. S3: Uh..Uh...Kodwa emuva ngicabanga ukuthi uma kukhulunywa ngeMother Tongue usuke ubheka emuva......(Uh..Uh... but your history, I think that if you speak about the Mother Tongue, you tend to look at the history/background)

20. ZL: ukuthi walifundanini? (As to when you learned it?)

21. S2: No.....

22. S3: usuke ubheka ibackground-asithi nje ama-Ancestors....(You have to look at the Background-let's just say your Ancestors)

In this example, although the matrix language is English initially, the Zulu lecturer switches to Zulu in turn 12 for a translation of the English, which, in turn, triggers a response in Zulu from S1 (turn 13), in spite of the fact that ZL continued in English in turn 12. The rest of this interaction remains in Zulu. The function of the code-switching on the part of the Zulu lecturer, in this case, was for purposes of clarification, instruction and explanation. This function is similar to that described elsewhere in the literature in relation to code-switching in South African schools (Adendorff 1993; Moodley 2003). Other functions identified in the literature include asserting solidarity and ingroup identity, framing of academic and pedagogic goals, and providing contextualization cues for introducing key concepts and related terms (Adendorff 1993). However, in the above interaction, the students chose to continue in Zulu (turns 15 - 24). One of the reasons for this could be that they found it easier to use their primary language to challenge what the lecturer was saying, and to present their own point of view (the language of the Ancestors - turn 22), i.e. the language was being used for argumentative purposes. This type of function can thus be added to the list of functions for which code-switching is used.

Students were free to use either English or Zulu in class sessions and were allowed to respond in either language in their examinations. Interestingly, many chose to interact in Zulu in class but wrote their assignments in English. One of the main points of focus of the research was 
how crucial concepts specific to the discipline of applied linguistics, and specifically language learning and teaching theory, were translated from English to Zulu, if at all, and how effectively these were communicated to the students as gauged from students' assignments and tests. The use of Zulu in class had not been circumscribed in any way so its use was not systematic or pre-planned, with the result that many of the concepts specific to the discipline were not necessarily translated into their equivalents in Zulu. An analysis of the data collected from audio-taped class sessions revealed that many of the terms for the discipline-specific concepts being taught on the course were not translated as terms. Rather, paraphrase was used as a technique to facilitate understanding of the concepts, and the English terms themselves were rendered as borrowings, such as uya-overgeneraliza (she is overgeneralizing) or iChunk (the chunk) for concepts such as overgeneralization and chunk (formulaic speech). The following excerpt from a class session on error analysis demonstrates this point. The lecturers and students were using a worksheet showing different types of 'errors' at four different time periods. The Applied linguistics lecturer was attempting to explain the difference between formulaic and creative speech (Ellis 1994) in relation to interlanguage - a crucial concept in second language acquisition research. The Zulu lecturer then attempted the explanation in Zulu. (The texts in parentheses are either full forms of the examples given in Zulu, or English translations of those forms).

[Key: AL: Applied Linguistics lecturer; ZL: Zulu lecturer; S1: Student 1]

1. AL: What I am trying to get you to understand is that ...Times 3 and 4 characterize a different type of speech but there is overlap....you still get the chunks mixed in with something more creative. If Times 1 and 2 are formulaic, then Times 3 and 4 are creative....creative speech.....both times, in English and in isiZulu, and they are creative for a reason.....

2. S1:(interrupting)...uh..I would like to ...to go back a little bit.....I'm not too sure about ...(indistinct)...I'm not too sure (about) chunk...?

3. AL: A chunk means 'unit', a 'whole'.....the parts in the whole are not recognized..... 
...Use of an African Language as a Language of Learning and Teaching ...

4. ZL: See...you see...when you say mus'ganga (musa ukuganga) or ngishaya wena (ngizokushaya) eSizulwini uma umfundi efunda ulimi, wakuzwa lokho, wezwa wena ukhuluma, ukhuluma nomunye, wabamba leyo nto, wayibamba unomphela, noma iright noma iwrong, kodwa iphelele yona kodwa ngokuzwa kwakhe wezwa sengathi yigama elilodwa, wakuhlanganisa wakwenza igama elilodwa, ukuthi kungamagama ahlukene, akakwazi lokho......Uzothola ukuthi lo’ u-akekho'....umfundi usebenzisa lo' akekho' noma yilaphi..wezwa wena ufika uthi 'uphi umama wakho?' wathi omunye 'akekho' ......Uma usumbuza ' iphi inja?', uzothi 'akekho'.... uya-overgeneraliza as well kodwa wamfunda as i-chunk. Uyezwa-ke? Akakwazi uku...akayazi imithetho yolimi.

[See...you see...when you say mus'ganga ('Don't be naughty') or ngishaya wena ('I'm going to smack you') ...in isiZulu, when a learner learns a language, s/he heard this (phrase), s/he heard you speak, you speaking to someone, s/he caught that 'thing' (chunk), s/he truly caught it (picked it up), whether right or wrong, but it is complete.....but, according to his/her hearing (perception), s/he perceives it as one word. S/he puts it together and makes one word; that the words are separate, s/he doesn't know that.....You will find that the akekho (s/he is not there).....the student will use akekho anywhere...s/he heard you arrive and say 'Where is your mother?' and the other person said 'akekho' (She is not here)....When you then ask 'Where is the dog?', s/he will say 'Akekho' ...S/he overgeneralizes as well because s/he learned it as a chunk. Do you understand? S/he doesn't understand to (indistinct)...s/he does not know the rules of the language.]

In the extract above, the concepts of a chunk and overgeneralization are explained, but no specific terms are provided for them in Zulu. One of the reasons for this was that there was very little existing terminology in Zulu for those concepts at that time. One of the reasons for designing the course this way was to develop the discourse of the discipline in Zulu as the course progressed. Terminology development in the applied linguistics discipline was thus grounded in our experience of teaching the course, although this development only began in earnest once the Zulu lecturer had begun to teach the course on her own in subsequent years. In this latter situation, Zulu was 
used predominantly as LoLT, which facilitated the natural, more organic development of the terminology used on the course. This approach to the creation of discipline-specific terminology is similar to that described by Ramani et al (2007) discussed earlier in this article.

Allowing the students the freedom to respond in the language of their choice both in class and in assignments and tests highlighted the challenges facing educators attempting to use an indigenous African language as the language of learning and teaching (LOLT). At times ambiguity arose where students chose to write assignments and exams in Zulu as opposed to English. Where the English terms had not been given equivalent terms in Zulu during class instruction, answers to questions involving these concepts tended to be non-specific. It was therefore difficult to assess whether students had, indeed, understood the concepts correctly. For example, students would use paraphrase or qualifiers (Halliday \& Mattiessen 2004; Wildsmith-Cromarty 2008) and general, 'everyday' terms which were underdifferentiated in terms of the more specific meanings carried by these concepts.

In order to probe this phenomenon more deeply, two practical assignments were set which tested knowledge of key concepts in the discipline, and which students had to respond to in both Zulu and English. In this way a comparison could be made of their descriptions of the concepts in both languages. The first assignment asked students to explain in which ways individual learners can differ in their approach to language learning in terms of both cognitive and affective variables. The second assignment asked for a one-page summary describing and explaining the various theories of second language acquisition.

The results of this exercise were mixed. Some students experienced difficulty expressing the concepts with adequate precision in Zulu as the following extract from a student's essay on cognitive strategies demonstrates.

\section{Example 2}

Student 1: isiZulu

Indlela yokucabanga ihambisana nezindlela zokufunda lapho umfundi akwazi ukubamba izinto azifundisiwe ngaphansi kwale ndlela yokucabanga. Abafundi bangahlukahluka ngezindlela zokufunda. 
(A method of thinking goes together with (is related to) a way of learning where the learner is able to catch (pick up) things that s/he is taught in terms of this method of thinking. Learners can differ according to the ways of learning.)

\section{Student 1: English}

The cognitive factors has (sic) to do with the learning strategies and the way they conceive (perceivel conceptualize?) the information. Under cognitive factors the learners can differ according to their learning styles.

The English version of this student's response contains the appropriate terminology for describing and discussing the concepts in question, i.e. cognitive factors and learning styles. However, the Zulu version does not reveal whether, in reality, the student has really understood these concepts. The concept of cognitive strategies is paraphrased as 'method of thinking' which, although related to the concept, is non-specific. In addition, the concepts of learning styles and learning strategies, which refer to different processes, are rendered indistinguishable by the same description-'ways of learning'. Having access to the appropriate terminology in Zulu in this particular case might have rendered the expression of this distinction clearer. In addition, the word indlela may be translated in a number of ways in English, depending on the context. It translates as 'style', 'way', 'approach', 'path', 'method', 'strategy', to name a few. Thus, certain concepts and related terms in English were under-differentiated when translated into Zulu, and this caused the two versions of the essay to vary in the accuracy of the information they expressed. This, in turn, had to do with the existence (or lack) of the relevant terms to express discipline-specific concepts.

Some results, however, were unexpected and challenged our growing conviction that students could not demonstrate adequate understanding of the relevant concepts without access to the appropriate terminology in Zulu. In some cases, the use of paraphrase actually revealed a deeper understanding of the concepts in question, because of the need for greater contextualization which covered the key semantic features of the concepts in the absence of the appropriate terminology. The following example contains extracts from two essays on theories of second language acquisition — one in English and the 
other in Zulu, both from the same student, as in Example 1.

\section{Example 3}

Student 2: isiZulu

iNativism Theory iveza ukuthi lento yinto evele ikhona ngaphakathi kumfundi. Ukukhuluma noma ukubhala kubonakala njengomphumela wolwazi vele obelukhona. Lapha sithola isakhi esibizwa LAD esisiza ikakhulukazi eminyakeni kusuka ku 0 kuya 11. Lokho umfundi uzalwa nakho.

\section{Student 2: English}

(Nativism theory shows that this thing is already there within the learner. Talking or speaking is visible as an outcome (as a result) of knowledge which was already present. Here we find the structure which is called the LAD which helps especially in the years starting from 0 to 11 . That, a student is born with it.)

\section{Student 2: English}

Nativism theory suggests that learners learn through internalizing without having to speak or write. A learner's speech or writing is seen as the product of internalization. A learner uses very overgeneralized contexts. The LAD helps the learner to grasp new knowledge and (it) must be made clear that it is an innate ability. It operates critically in the period between 0 - 11 years.

Although both descriptions demonstrate an understanding of the LAD (Language Acquisition Device) (Chomsky 1965) as a facilitating structure in the early years up to eleven, the English version does not make clear what the student means by 'internalizing without having to read or write'. Conversely, in the Zulu version, language (talking or speaking) is said to come about as a result of already existing, innate knowledge, whereas the English version seems to indicate that the learner actively internalizes the information. There is thus a discrepancy in the information provided in the two versions. It is also not clear what the student means by 'overgeneralized contexts' in the English version. It would appear that, in this case, the provision of 
terminology, rather than facilitating understanding for the student, has only served to obscure the essential meaning of the concepts. The Zulu version in this example has been able to avoid masking lack of understanding through the use of technical terminology because there was none. Instead, it managed to reveal the student's true understanding of the concept because it was paraphrased in simpler terms.

What the above examples show is that it is certainly possible for students to make use of their mother tongue to express their understanding of what they have been taught without necessarily having the appropriate terminology at hand. However, coining appropriate terms is more economical for both teaching and learning in the longer term, and this is what the SANTED project has set out to accomplish.

The terminology development aspect of the course described above provided the impetus for Phase 3 of the Sustainability Model for use in the SANTED project. However, in order to avoid confusion over key disciplinespecific concepts, a principled decision was taken to translate selected course materials into Zulu beforehand for use in tutorials. This is a more proactive approach than that described above as it involves the initial development of terms before their presentation in tutorials or materials, rather than allowing a purely organic development in class, from the bottom up, as the need arises. Furthermore, this development takes place in the context of workshops with various stakeholders, including students, which thus represents a more participatory approach. This is appropriate for the purposes of the SANTED project, which are to drive the intellectualisation and development of an African language as a LoLT, so it may be used as a tool to facilitate and enhance learning.

\section{Conclusion}

This article has described the gradual development of a Sustainability Model for language acquisition and development over a number of years. It has described each of the research studies on various aspects of the acquisition and teaching of Zulu which have made a specific contribution to the development of the model. This organic development has only become clear with hindsight and with the conceptualization and implementation of the model in the current SANTED project which draws indirectly on the findings of the previous research projects. 
An interesting aspect of the third research study was the fact that both specialists were also each other's students. The applied linguist was enrolled for a major in Zulu at the time, with the Zulu specialist as one of her teachers, and was thus indirectly both testing and increasing her knowledge of the language through teaching on the course within a psycholinguistic framework. Through her exposure to the applied linguist as a learner, the Zulu specialist, in turn, had become interested in the theories applicable to language learning and teaching and subsequently registered for a Masters degree in Applied Language Studies with the applied linguist as her supervisor. This created a mutually enriching and supportive environment where everyone was both a learner and teacher (Wildsmith-Cromarty 2003a). Students on the course thus benefited from dynamic interactions between the two specialists that interrogated language practices, methodologies and theories. As a consequence of this, the Zulu specialist now leads the language acquisition component of the sustainability model for the SANTED project, in collaboration with the researcher. All the knowledge and expertise gained from her collaboration with the researcher in the above-mentioned research projects have culminated in the implementation of the model based on her experience of teaching Zulu as an additional language and teaching others how to teach Zulu as an additional language. In the light of this, the development of what has become a Sustainability Model for language acquisition and development has been truly organic and grounded in research. What is needed next is a report on the findings of the implementation of the model in the contexts selected for the SANTED research project. For example, further research needs to be undertaken of the classroom contexts where Zulu is being introduced as medium of instruction in content subjects such as Psychology, Health Sciences, Nursing and Education.

- I wish to acknowledge the contribution to this article of my colleague and Zulu teacher, Mary Gordon, who provided substantial input in relation to the transcriptions and translations of the isiZulu sections. I also wish to acknowledge the sponsorship of SANTED for making the multilingualism project a reality. 
...Use of an African Language as a Language of Learning and Teaching ...

\section{References}

Adendorff, Ralph D 1993. Teacher Education: Code-switching amongst Zulu-speaking Pupils and their Teachers. South African Journal of Applied Language Studies 2:1,13 - 26.

Brinton, DM, MA Snow \& MB Wesche 1989. Content-based Second Language Instruction. New York: Newbury House.

Chomsky, Noam 1965. Aspects of the Theory of Syntax. Cambridge, Mass.: MIT Press.

Cummins, Jim 2000. Language, Power \& Pedagogy: Bilingual Children in the Crossfire. Clevedon, UK: Multilingual Matters.

Doughty, Catherine \& Michael Long 2003. The Scope of Inquiry and Goals of SLA. In Doughty, Catherine \& Michael Long (eds): The Handbook of Second Language Acquisition. Oxford: Blackwell.

Doughty, Catherine \& Michael Long (eds) 2003. The Handbook of Second Language Acquisition. Oxford: Blackwell.

Ellis, Rod 1985. Understanding Second Language Acquisition. Oxford: Oxford University Press.

Ellis, Rod 1994. The Study of Second Language Acquisition. Oxford: Oxford University Press.

Halliday, Michael \& Christine Mattiessen 2004. An Introduction to Functional Grammar ( $3^{\text {rd }}$ Ed). London: Arnold.

Krashen, Stephen 1985. The Input Hypothesis. London: Longman.

Luckett, Kathleen 1995. National Additive Multilingualism: Towards a Language Plan for South African Education. Cape Town: Mimeo.

Moodley, Visvaganthie 2003. Language Attitudes and Code-switching

Behaviour of Facilitators and Learners in Language, Literacy and Communication Senior Phase Outcomes Based Education Classrooms.

Unpublished doctoral thesis. University of Natal, Durban. South Africa.

Pienemann, M 2003. Language Processing Capacity. In Doughty, Catherine \& Michael Long (eds): The Handbook of Second Language Acquisition. Oxford: Blackwell.

Ramani, Esther, Kekana, Tebogo, Mamphago,Modiba \& Joseph, Michael 2007. Terminology Development versus Concept Development through Discourse: Insights from a Dual-medium BA Degree. Southern African Linguistics and Applied Language Studies 25,2: 207-223.

Romaine, Suzanne 2003. Variation. In Doughty, Catherine \& Michael Long 
(eds): Handbook of Second Language Acquisition. Oxford: Blackwell. SANTED Phase 11 Multilingualism Project 2006 Business Plan submitted jointly by the University of KwaZulu-Natal and the Durban University of Technology, KwaZulu-Natal.

Selinker, Larry 1992 Rediscovering Interlanguage. London: Longman.

Suzman, Susan 1991. Language Acquisition in Zulu. Unpublished doctoral thesis. University of the Witwatersrand, Johannesburg.

Suzman, Susan 1999. Learn Zulu the Way Children do. South African Journal of African Languages 19,2: 134-147.

Vygotsky, Lev 1978. Mind in Society: The Development of Higher Psychological Processes. Cole, M, V John-Steiner, S Scribner \& E Souberman (eds.). Cambridge, M.A: Harvard University Press.

Watson-Gegeo, K \& S Nielsen 2003. Language Socialization in SLA. In Doughty, Catherine \& Michael Long (eds) 2003. The Handbook of Second Language Acquisition. Oxford: Blackwell.

Wildsmith, Rosemary, Mary Gordon \& Mary Godlonton 2007. African Language Curriculum Reform at Tertiary Level from both Learners' and Teachers' Perspectives. Paper presented at the $38^{\text {th }}$ Annual Conference and the $11^{\text {th }}$ Annual Conference of the African Language Teacher's Association, March 2007. University of Florida, Gainesville.

Wildsmith-Cromarty, Rosemary 2003a. Mutual Apprenticeship in the Learning and Teaching of an Additional Language. Language and Education 17,2: 138-154.

Wildsmith-Cromarty, Rosemary 2003b. Do Learners Learn Zulu the Way Children do? A Response to Suzman. South African Journal of African Languages 23,3: 175-188.

Wildsmith-Cromarty, Rosemary 2008. Can Academic/ Scientific Discourse Really be Translated across English and African Languages? Southern African Linguistics and Applied Language Studies 26,1: 147-169.

Rosemary Wildsmith School of Language, Literature \& Linguistics University of KwaZulu-Natal Wildsmithr@ukzn.ac.a 